Portland State University

PDXScholar

\title{
The Influence of Hydrogen-Argon Mixed Gases on Electro-spark Deposition
}

Thomas Langston

Portland State University

Follow this and additional works at: https://pdxscholar.library.pdx.edu/honorstheses

\section{Let us know how access to this document benefits you.}

\section{Recommended Citation}

Langston, Thomas, "The Influence of Hydrogen-Argon Mixed Gases on Electro-spark Deposition" (2016).

University Honors Theses. Paper 284.

https://doi.org/10.15760/honors.318

This Thesis is brought to you for free and open access. It has been accepted for inclusion in University Honors Theses by an authorized administrator of PDXScholar. Please contact us if we can make this document more accessible: pdxscholar@pdx.edu. 
The Influence of Hydrogen-Argon Mixed Gases on Electro-spark Deposition

Author: Thomas Langston

Advisor: William Wood

Portland State University 


\section{Introduction}

ESD is a micro welding additive technology that deposits small amounts of molten metal onto a substrate. In order to achieve this, ESD uses capacitors to provide a 50-75 $\mu \mathrm{s}$ duration, high voltage electrical pulse through a depositing electrode in contact with a metal substrate. The contact area is locally heated to melt small amounts of the electrode material and substrate to bond the two together. The resultant microstructure from short pulse duration and high cooling rates along with the ability to deposit dissimilar metals onto one another makes this process candidate for tribological and corrosion prevention applications. Though an optimized dissimilar metal ESD surface layer requires careful alloy design, harder and more corrosion resistant alloys can be deposited onto softer and more reactive substrates for a wide range of applications. The studies on the use of this process for tool hard facing and pump cavitation wear improvement have been studied ind $_{1,2}$.

This study used a $316 \mathrm{~L}$ stainless steel electrode to deposit onto 304 stainless steel. Elemental chemistry markers of varying molybdenum and nickel in $316 \mathrm{~L}$ compared to 304 stainless steel allowed SEM/EDS to show the nature of substrate-electrode mixing and diffusion in the deposit.

There are challenges to the ESD process that limit the use of this technology and its convenience. Since there is such a low volume transfer during the process, the deposition rate is very low. Depositing a substantial coating process for even an area of a few square inches of equipment can take several hours of processing. When ESD is used for multiple layers the surface becomes rough due to uneven deposit build up. Accumulation of oxides on the surface and surroundings of the deposition is more pronounced in air and can lead to unwanted inclusions and defects in the coating. Hydrogen addition to argon shielding gas is of interest for its capability to increase heat localization, weld cleanliness, and penetration in many welding applications. This study evaluates the benefits of dilute hydrogen shielding gases for the electro spark deposition processes.

\section{Literature Review}

Research by Tusek and $\mathrm{Suban}_{3}$ has shown that argonhydrogen mixed gas increases arc stability and penetration during gas metal arc welding of stainless steel. The use of hydrogen containing forming gas has long been a trade technique for altering the characteristics of a weld. However, there is little published literature that documents specifically the effects of forming gas on ESD. Investigations of the use of argon and helium shield gases during ESD of Tungsten
Carbide and Titanium Carbide resulted in varying differences of deposition efficiency across different energy levels ${ }_{4}$.

Studies by Nordstrom 5 showed that the deposition quality is highly variable with multiple directly correlative parameters such as power or voltage, electrode downforce, and surface roughness ${ }_{5}$ Commonly process parameters have varying significance in the deposition characteristics depending on the multiple other conditions and parameter settings.

A study by Niedner-Boman ${ }_{6}$ suggested that a hydrogen shielding gas increases pulse duration. This was considered an indicator the shielding gas may change the amount of heat input based on the time duration of the electrical input process. Acquiring data that details the specific dynamics of heat input during the deposition process was a goal of this experiment.

Thamer $_{7}$ et. al. observed the build-up mechanism of multi-layered depositions by showing that the profile of the surface being deposited upon is very influential on the deposition rate and quality. Once the first layer is deposited the following layers of material tend to build up in peaks and result in a progressively rougher surface. Thamer found that this rough surface, even after the first pass, causes deposition rate to decrease. Price et $\mathrm{al}_{8}$ noticed the same behavior her experiment and evaluated the use of ultrasonic impact treatment (UIT) to remedy the problem. This method employs the use of an ultrasonically operated impact hammer to flatten out the peaks that build up during deposition. She found that the use of UIT increased deposition rate for the following layers.

Tang S. $\mathrm{K}_{9}$ et. al. evaluated the quality of deposition and deposition rates throughout the ESD material build up process. Measurements of the electrode weight and substrate weight before and after deposition were recorded to see if any material was lost due to arc instability and splattering. From this process mass transfer and deposition rate was calculated. They also examined the depositions with a scanning electron microscope to reveal deposition details. Both Price and Tang sectioned specimens through the deposition section for lateral examination of deposition depth. Nordstrom determined the percent porosity of a deposit with the same crosssectioning method. The current study measured the effects a modified shielding gas has on electrode temperature, process acoustic signature, splat quality and microstructure for a multilayer deposition. 


\section{Materials Selection}

A 316L stainless steel electrode was selected for its oxidation and corrosion resistance. A 304 stainless steel substrate was selected for its availability and common use. Similar electrode and substrate alloys tend to deposit with fewer defects and better quality across a wider range of parameter settings. The molybdenum content in $316 \mathrm{~L}$ has a similar metallurgical role similar to silicon in that it resists corrosion by preventing iron diffusion and providing better oxide scale adherence ${ }_{10}$. Typical material composition and properties are listed in Tables 1 and 2 . Gas Properties are listed in Table 3.

Table 1: Typical Material Composition (Weight \%)

\begin{tabular}{|l|r|r|}
\hline Element & 316L & \multicolumn{1}{|c|}{$\mathbf{3 0 4}$} \\
\hline Carbon & $<=.03$ & $<=0.08$ \\
\hline Chromium & $16-18$ & $18-20$ \\
\hline Iron & $62-72$ & $65-74$ \\
\hline Manganese & $<=2.0$ & 2 \\
\hline Molybdenum & $2.0-3.0$ & 0 \\
\hline Nickel & $10-14$ & $8-12$ \\
\hline Nitrogen & $<=0.010$ & $<=0.10$ \\
\hline Phosphorous & $<=0.045$ & $<=0.045$ \\
\hline Silicon & $<=0.75$ & $<=0.75$ \\
\hline Sulfur & $<=0.030$ & $<=0.030$ \\
\hline
\end{tabular}

Table 2: Material Properties

\begin{tabular}{|l|l|l|}
\hline Property & $316 \mathrm{~L}$ & 304 \\
\hline $\begin{array}{l}\text { Electrical Resistivity } \\
\text { (micro-ohm-cm) }\end{array}$ & 74 & 72 \\
\hline $\begin{array}{l}\text { Specific Heat } \\
\text { Capacity }\left(\mathrm{J} / \mathrm{g}-{ }^{\circ} \mathrm{C}\right)\end{array}$ & 0.500 & 0.500 \\
\hline $\begin{array}{l}\text { Thermal Conductivity } \\
\left(\mathrm{W} / \mathrm{m}^{\circ}{ }^{\circ} \mathrm{K}\right)\end{array}$ & 16.2 & 16.2 \\
\hline $\begin{array}{l}\text { Liquidus } \\
\text { Temperature }\left({ }^{\circ} \mathrm{C}\right)\end{array}$ & 1399 & 1454 \\
\hline $\begin{array}{l}\text { Solidus Temperature } \\
\left({ }^{\circ} \mathrm{C}\right)\end{array}$ & 1371 & 1399 \\
\hline $\begin{array}{l}\text { Density } \\
\text { (g/cc) }\end{array}$ & 7.99 & 8.03 \\
\hline
\end{tabular}

Table 3: Gas Properties

\begin{tabular}{|l|l|l|l|}
\hline Property & Air & $\mathrm{Ar}$ & $\mathrm{H}_{2}$ \\
\hline $\begin{array}{l}\text { Density } \\
\left(\mathrm{kg} / \mathrm{m}^{\wedge} 3\right)\end{array}$ & 1.275 & 1.669 & .085 \\
\hline $\begin{array}{l}\text { Conductivity } \\
\text { (J/msecK) }\end{array}$ & 0.026 & .016 & 0.18 \\
\hline $\begin{array}{l}\text { lonization } \\
\text { Energy } \\
\text { (Kj/mol) }\end{array}$ & $\sim 1400$ & 1520 & 1488 \\
\hline
\end{tabular}

\section{Methodology}

To create deposition samples an ESD torch with a continuously rotating electrode torch connected to an Advanced Surfaces and Processes (ASAP) ESD power source traversed a coupon in a linear path. Electrode torch motion across the substrate surface was made reproducible and adjustable by a programmable XRCMoto-Man controller with a 5-axis robotic arm. A shielding gas cup was used to direct the gases onto the electrode, Figures 1, 2 and 3. When the system was run in air no gas was applied through the cup. A Pushcorps pneumatically controlled force applicator system maintained electrode contact with the substrate with a constant down force.

Shielding gas conditions were varied from an air to a $100 \%$ Ar flowing shield gas and to a $95 \% / 5 \% \mathrm{Ar} / \mathrm{H} 2$. The settings used in the ESD system set up are shown in Table 4.

Audio frequency distributions were recorded using a True RTA frequency analyzing program. Electrode temperature was recorded using a non-contact Raytech IR sensor mounted stationary in the direct path of the electrode motion (SN: RAYMA2SBCF). This allowed the temperature to be recorded on the rotating and linearly translating electrode. The location of the temperature measurement is 0.125 inches from the electrode tip.

Table 4: ESD Parameters

\begin{tabular}{|l|l|}
\hline Voltage & $100 \mathrm{~V}$ \\
\hline Current & $4.3 \mathrm{~A}$ \\
\hline Capacitance & $40 \mu \mathrm{F}$ \\
\hline Approximate Pulse Duration & $30 \mu \mathrm{s}$ \\
\hline Pulse Frequency & $500 \mathrm{~Hz}$ \\
\hline Gas flow-rate (100\% Ar) & $20 \mathrm{cfm}$ \\
\hline Electrode stick-out & $0.5 \mathrm{in}$. \\
\hline Electrode diameter & $0.125 \mathrm{in}$. \\
\hline Down Force & $9 \mathrm{oz}$. \\
\hline IR beam distance to electrode tip & $0.125 \mathrm{in}$. \\
\hline
\end{tabular}

Both single splat and multilayered depositions were produced using different shield gases. The number of passes of the electrode for each test is detailed in Table 5. Single splats were imaged as deposited while crosssection samples were prepared using an automated Struers Rotopol polisher. The Kallings etchant used in step 5 is a solution of $40 \mathrm{ml}$ of de-ionized water, 2 grams of copper chloride, $40 \mathrm{ml}$ hydrochloric acid and $40 \mathrm{~m}$ ethanol. The polishing and etching steps are shown in Table 6. 
Table 5: Number of Electrode Passes Per Test

\begin{tabular}{|l|l|}
\hline Test Category & $\begin{array}{l}\text { Number of electrode } \\
\text { passes }\end{array}$ \\
\hline Audio & 1 \\
\hline Visual & 1 \\
\hline Temperature & 7 \\
\hline SEM cross -sections & 7 \\
\hline Single Splats & 1 \\
\hline
\end{tabular}

Table 6: Sample Preparation Steps

\begin{tabular}{|l|l|l|}
\hline Step & Description & Duration \\
\hline 1 & Wet Grind 220 grit & $4 \mathrm{~min}$. \\
\hline 2 & Polish $9 \mu \mathrm{m}$ & $5 \mathrm{~min}$. \\
\hline 3 & Polish $3 \mu \mathrm{m}$ & $5 \mathrm{~min}$. \\
\hline 4 & Polish $0.04 \mu \mathrm{m}$ & $4 \mathrm{~min}$. \\
\hline 5 & Etch Kallings & $7 \mathrm{sec}$. \\
\hline
\end{tabular}

Single splat samples were imaged under an Olympus optical metallograph equipped with a Nomarski prism. SEM cross-section and splat images were produced using a Zeiss SEM Secondary Electron Detector. EDS results were made using an Oxford Instruments EDS spectrometer attached to the same SEM.

\section{Results}

High speed video results provided the opportunity to observe individual discharge events at 10,000 frames per second. Discharges made in air exhibited significant amounts of molten material being ejected with each discharge event. The effects of the shielding gases are seen in Figures 2 and 3. The visual discharge characteristics of the Argon and Argon-Hydrogen gases are nearly indistiguishable. Both gases create a quieter blue ionized gas discharge.

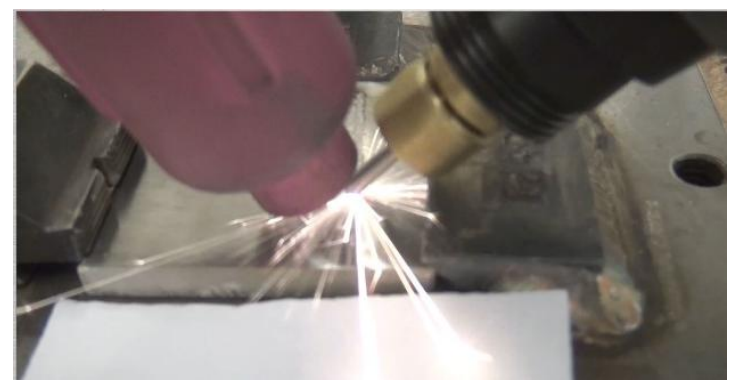

Figure 1: Absence of shielding gas

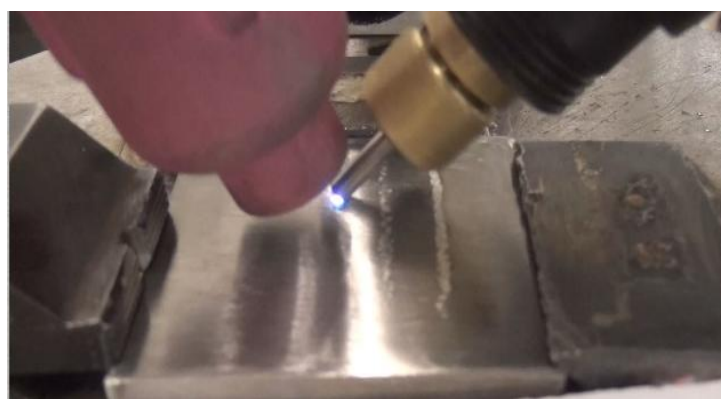

Figure 2: Argon shielding gas

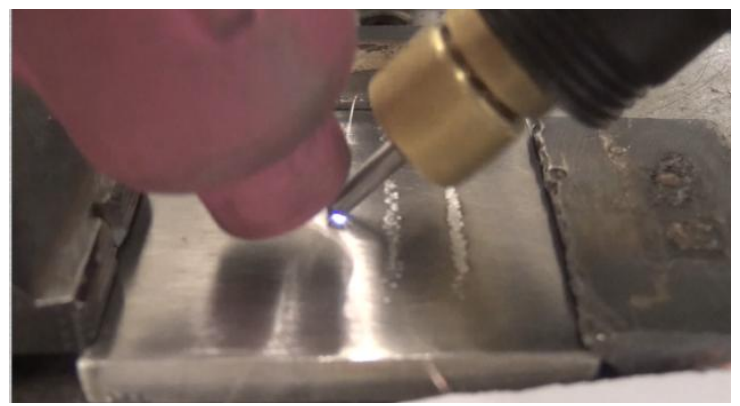

Figure 3: 95\%/5\% Ar/H2

The audio frequency spectrum recordings were sampled 10 times. Figure 4 shows select frequencies that displayed the greatest average difference in amplitude for varying shielding gas conditions. Figure 5 shows amplitudes of select frequencies with the smallest amount of variance in data, i.e. the results with the most consistent signal.

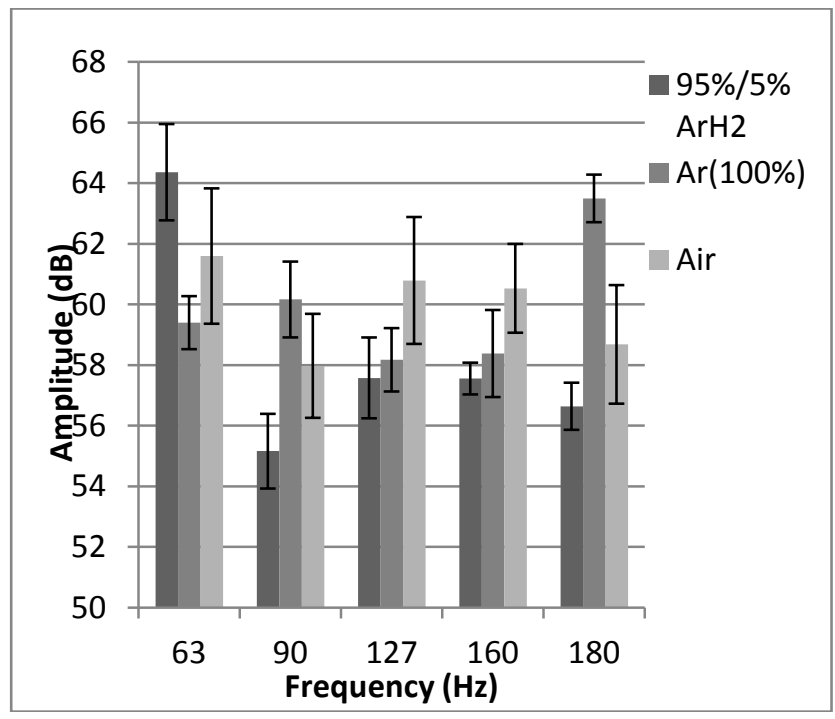

Figure 4: Transient Frequency Distribution 
Recordable differences in amplitude reached a maximum of $6 \mathrm{~dB}$. The amplitude difference between air and shielding gas conditions were significant enough to hear, however the audible difference between argon and argon hydrogen gases may only be detected with an appropriate microphone and frequency analysis.

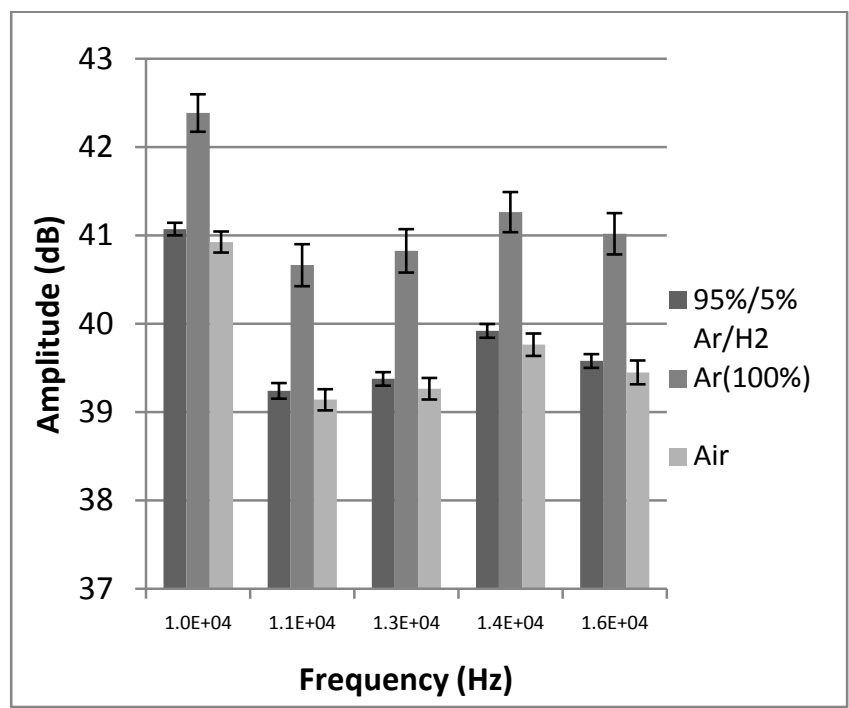

Figure 5: Low Variance Frequency Distribution

Electrode temperature for 7 passes of the torch assembly is depicted in Figures 6. Electrode temperature was lowest when using the $95 / 5$ shield gas condition, coming to a quasi-steady-state slightly above 370 degrees $C$. The electrode reached a quasi-steady-state temperature of 390 degrees $\mathrm{C}$ in the Argon gas. No temperature profile is shown for the test in air, but the electrode reached a maximum steady state temperature of $700{ }^{\circ} \mathrm{C}$ after 17 passes of the electrode.

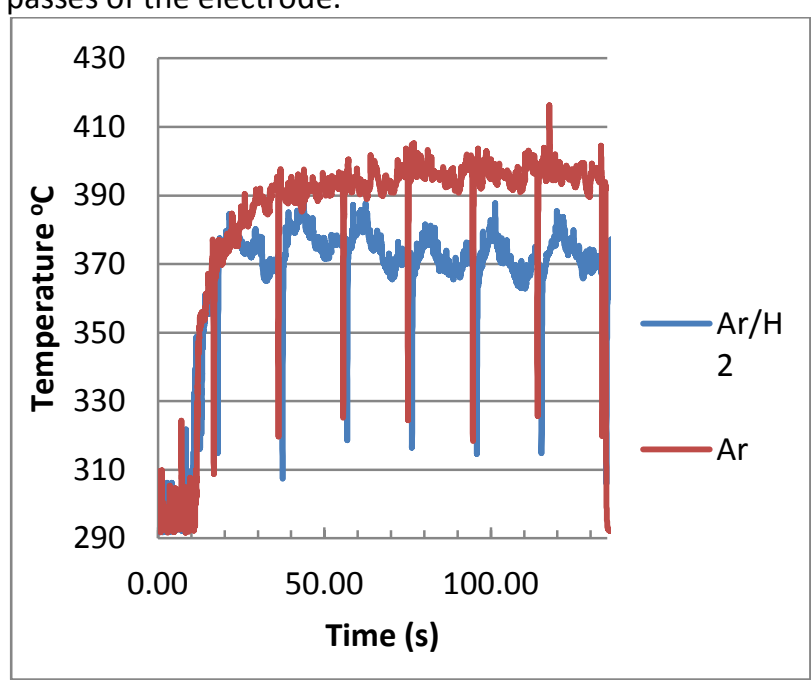

Figure 6: Temperature Data for 7 Electrode Passes
Images of individual deposition splats on 304 stainless steel are detailed in Figures 7-13. These images show splat topography at the level of the substrate. SEM and LOM images show the different splat characteristics for the different shielding gases. Smoother depositions found for both shielding gas conditions were not found in air conditions. Gashes in the substrate as seen in figure 8 were also more common when no shielding gas was present. These are due to abrasion between the electrode and substrate when smooth deposition is not occurring.

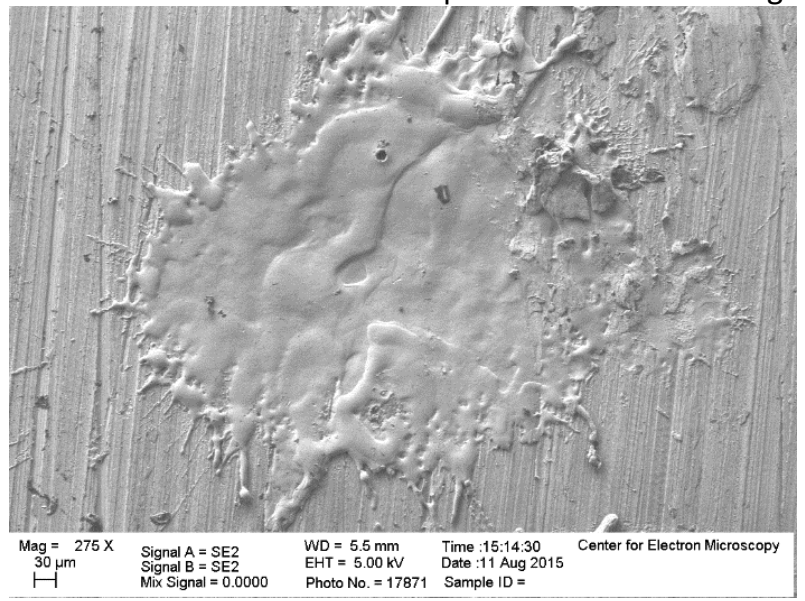

Figure 7: SEM Image of Single Splat made in still air

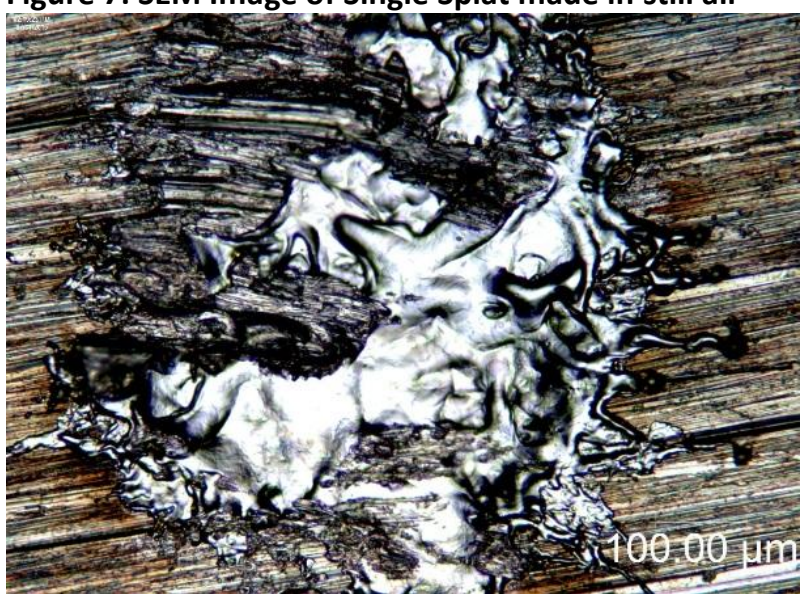

Figure 8: LOM image of Single Splat made in still air

The splats made in Argon were drastically different from the depositions made in air. In Argon, these tended to exhibit more surface wetting as seen in the periphery of the deposition in Figure 9. Also these depositions had few streams of ejected material and remained in cohesive flat splats. 


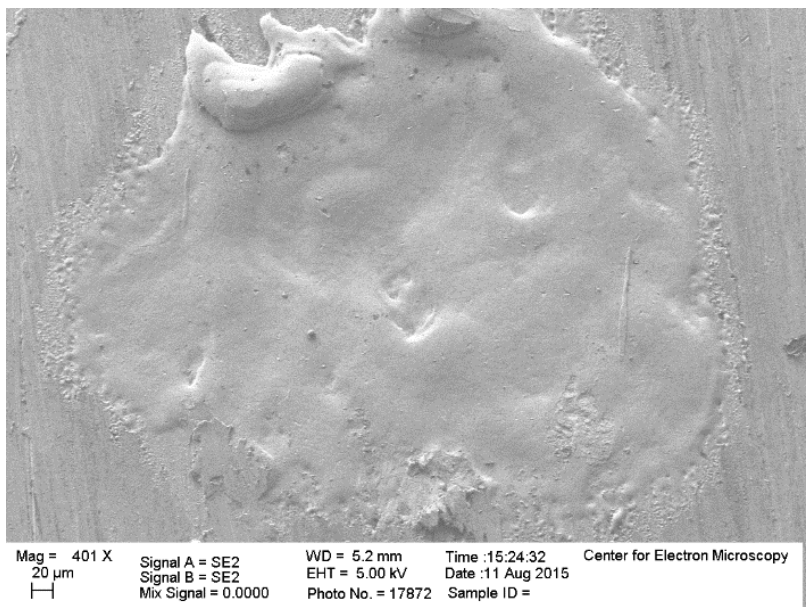

Figure 9: SEM Image of Single Splat made in Argon

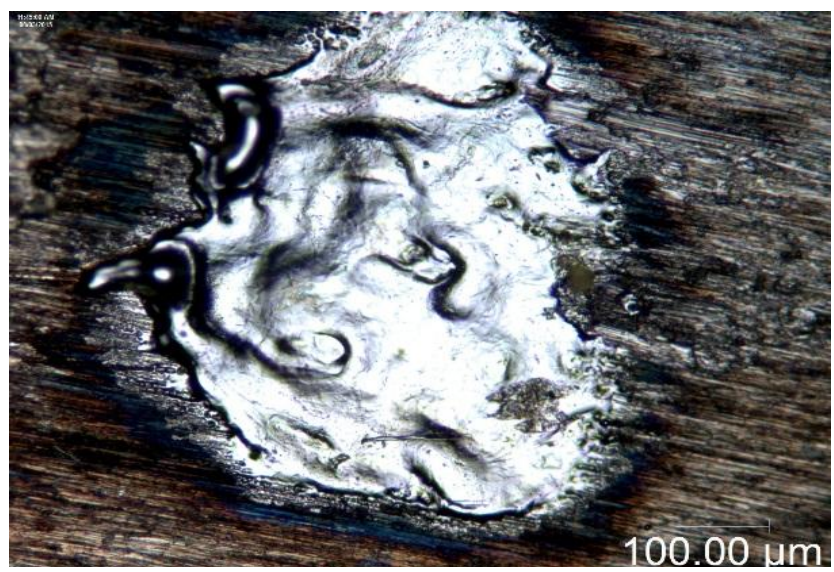

Figure 10: LOM Image of Single splat made in Argon

Depositions made in Argon-Hydrogen created more surface texture and less wetting at the outside edge of the deposition than depositions made in argon shield gases. These splats did not wet to the substrate surface as seen in the argon shielding gas conditions, but tended to built up at the edges.

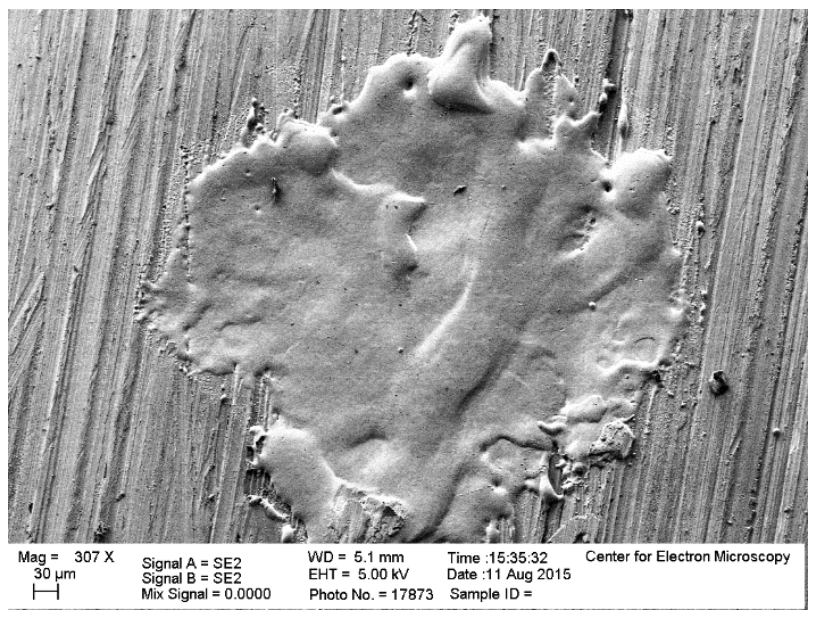

Figure 11: SEM Image of Single Splat made in 95/5 Ar/H2

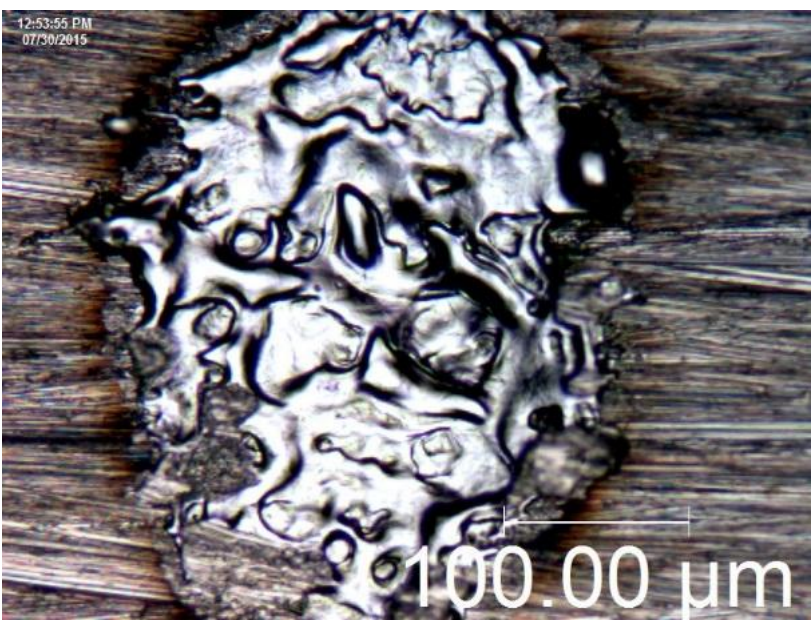

Figure 12: LOM Image of Single splat made in 95/5 Ar/H2

Cross-section images in Figures 13, 15 and 17 show microstructural characteristics of each deposition. SEMEDS line scans over the same images reveal elemental marker concentrations. Iron is displayed in red, molybdenum in pink and nickel in green. Secondary electron Images were produced with a $30 \mu \mathrm{m}$ aperture and $5 \mathrm{kV}$ accelerating voltage, while EDS results were made using a $60 \mu \mathrm{m}$ aperture at $15 \mathrm{kV}$.

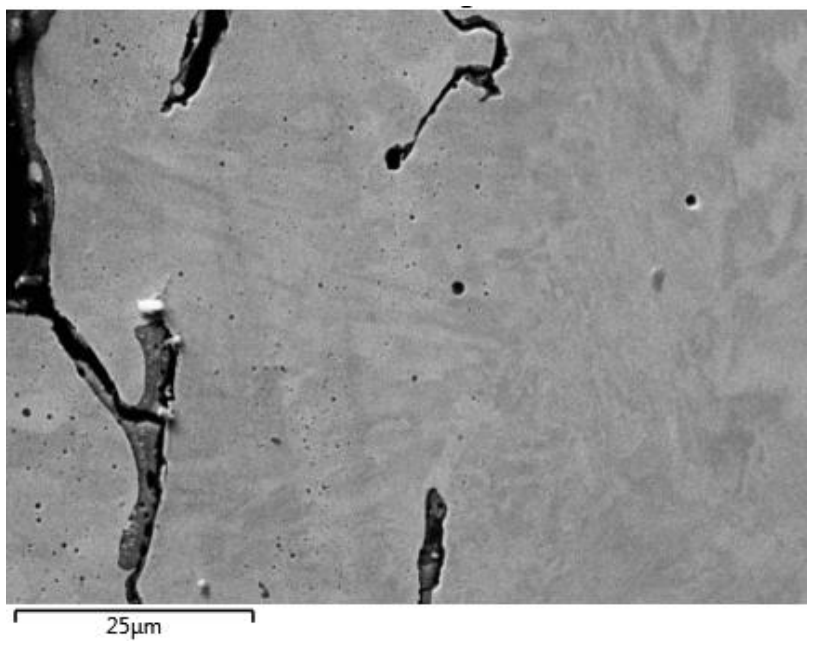

Figure 13: SEM image of multilayered deposition in air on the left

Depositions in air were consistently populated with high porosity and bridging defects between overlapping depositions. Material deposited in these conditions appeared to build up with multiple gaps between layers. Line scans indicate a $15 \mu \mathrm{m}$ elemental mixing zone. 


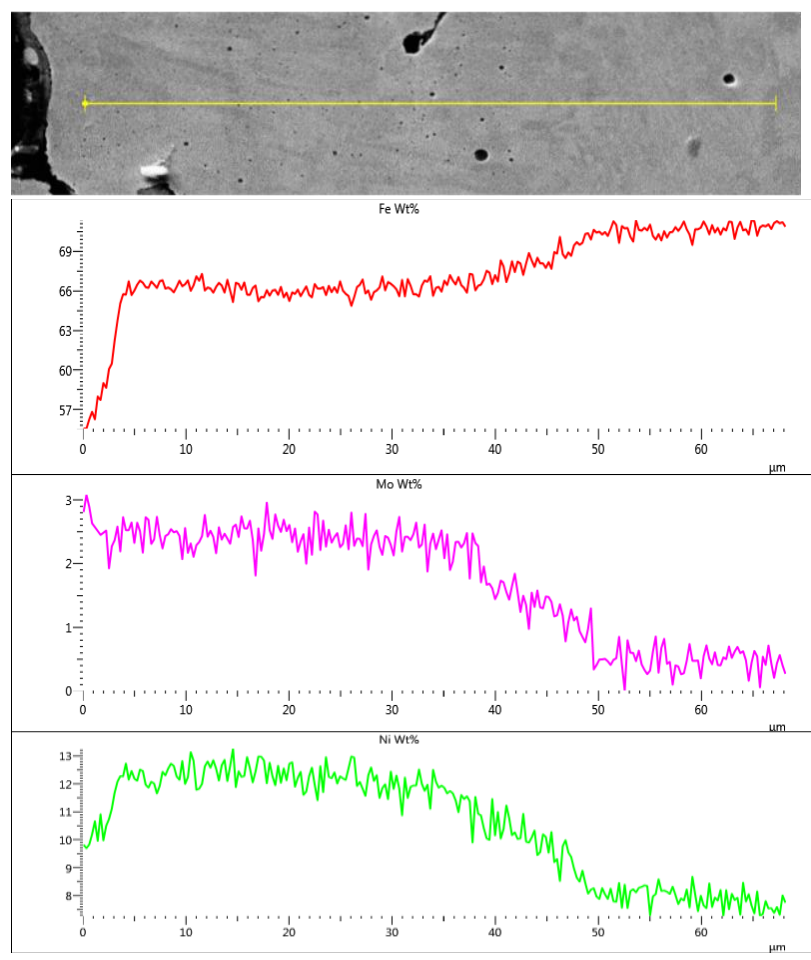

Figure 14: SEM-EDS elemental weight percentage linescan of multilayered deposition in air

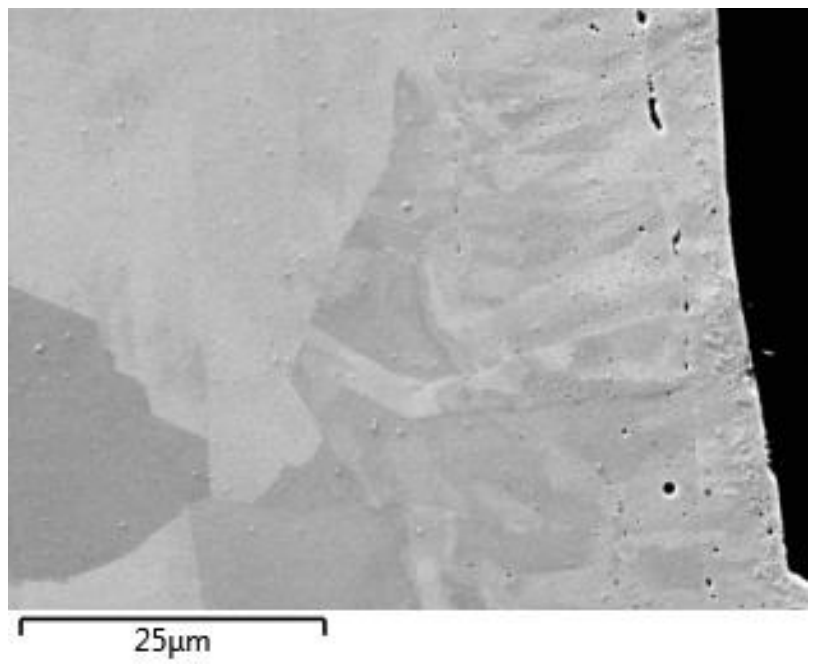

Figure 15: SEM image of multilayered deposition in argon on the right

Argon shielding gas depositions were much smoother and exhibited less porosity as well as fewer and smaller bridging defects. EDS results showed a smaller $13 \mu \mathrm{m}$ elemental mixing zone. In this deposition, fluctuations in the elemental concentration correspond to two smaller mixing zones.

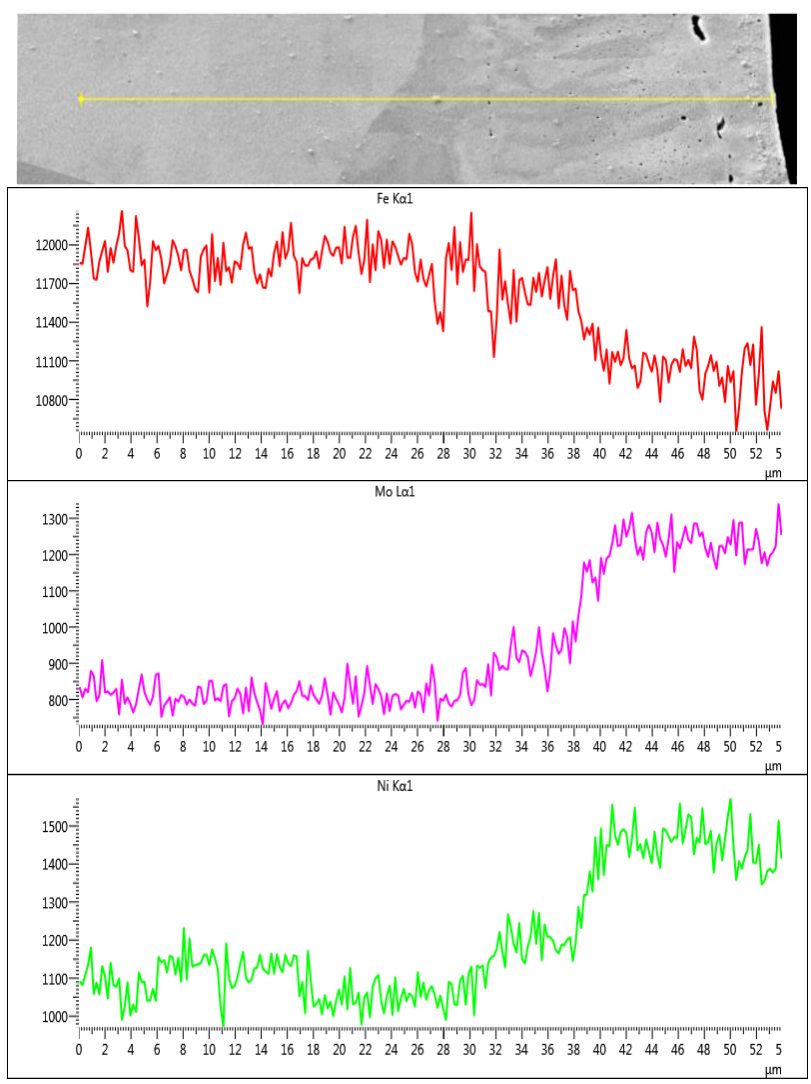

Figure 16: SEM-EDS elemental weight percent line-scan of multilayered deposition in $\mathrm{Ar}$

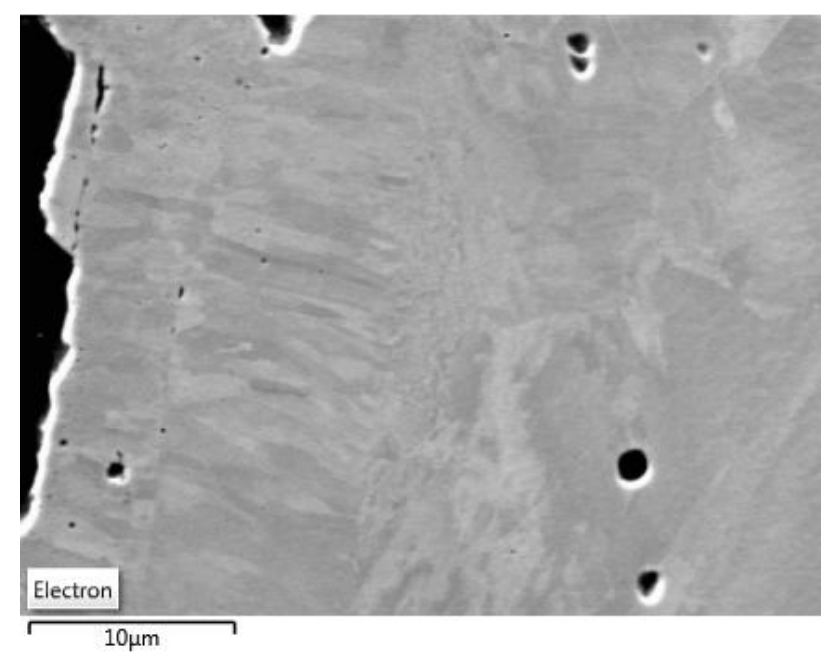

Figure 17: SEM Image of multilayer deposit in $\mathrm{Ar} / \mathrm{H}_{2}$ on the left

Depositions in argon-hydrogen shielding gas had higher porosity and fewer bridging defects than those in argon. EDS showed multiple more prominent elemental mixing zones spanning $15 \mu \mathrm{m}$ indicating that the substrate and electrode mix together multiple layers above the base metal. 


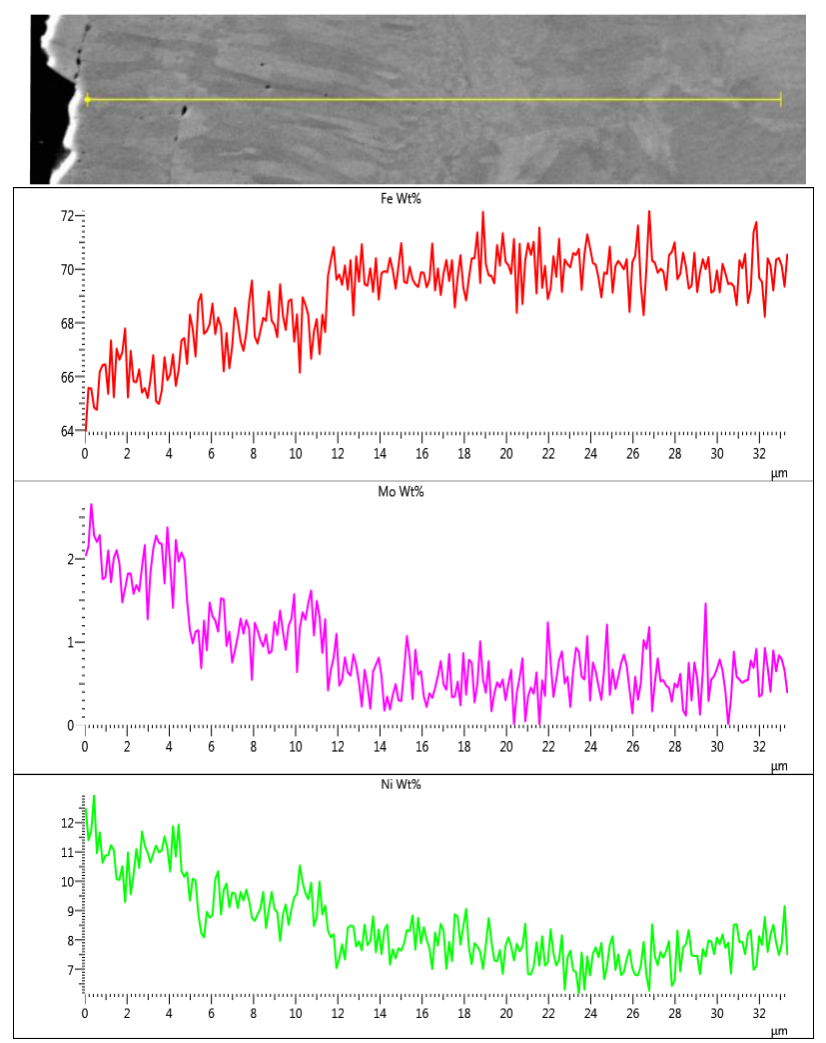

Figure 18: SEM-EDS elemental weight percent line-scan of multilayered deposition in $\mathrm{Ar} / \mathrm{H}_{2}$

\section{Discussion:}

Visual observation tests confirmed there was an observable difference between the discharges with and without a shielding gas. However there was not a clear difference between the discharges with a 95/5 Ar/H2 shielding gas and a pure Ar shielding gas. Without a shielding gas the electrode created more chaotic discharges and more molten material was ejected away from the substrate. For air conditions, the electrode tip emitted more light due to heating than either cooler ionized shielding gas discharges seen. Both shielding gases created the same visual effect of decreasing the amount of observable molten material and creating a more controlled blue colored ionized gas discharge.

High speed footage proved to be an applicable way to gage the effectiveness of a shielding gas. However for slight differences in shield gas it was proven insufficient to indicate shielding gas contribution to visual changes in the process.

Acoustic signature tests showed measureable differences in the discharge sound for different gas conditions. Though only audible differences between air and shielding gas conditions could be heard, the use of a () microphone allowed measuring the amplitude differences between 0 and 5\% Hydrogen concentration in an Argon shielding gas. The frequency spectrum recordings were limited to discrete data sampling did not allow transient signals to be separated from continuous ones. This was mostly due to interference from the noise of the controller operation. It is likely that the variations in signals have been detected for different shield gases however more samples are needed to decrease the error margin in the current data set. More physical noise barriers in the experimental recording space would also help to make measurements more effective.

Figure 6 indicates an electrode operating in ArgonHydrogen gas was typically 20 degrees cooler than when it is operating in Argon gas. This indicates that the free surface area in the Argon-Hydrogen conditions is surrounded by a more conductive gas applied by forced convection. Though this convective property may not be a strong factor for the heat input in a welding process, the ESD process, which has far lower duty cycle than conventional welding, is more susceptible to heat loss due to this factor. The duty cycle of this process is about 1.9\% at $40 \mu \mathrm{F}$ whereas typical welding applications have duty cycles greater than $30 \%$. Measured fluctuations in temperature lasted between 0.1 to 0.4 seconds. Since the approximate pulse duration for a $40 \mu \mathrm{F}$ setting is $37 \mu \mathrm{s}$, it was concluded that spikes in temperature were due to the vibration of the torch and electrode assembly and did not correlate with a temperature response due to individual discharge events.

Characterizing the type of material transfer that ESD facilitates was important to understanding the effects of varying parameters such as power input and change in shield gas composition. When characterizing the material transfer in GMAW and GTAW welding the International Institute of Welding considers globular transfer to be occurring when the molten material is cohesively attached to the electrode at a larger diameter than the electrode. Spray transfer is considered when molten material melts into drops that are smaller than the diameter of the electrode and are ejected from its surface onto the substrate. This is caused by a change in magnetic pinch pressure from the changing electric field in the electrode ${ }_{11}$. This is affected by the amount of current traveling through the ionized shield gas and electrode. Since molten material in ESD never makes it to the size of the electrode diameter all depositions are considered to be spray transfer depsitions. However different transfer characteristics still arise and are identified as follows. Rough surfaces are seen in depositions in air and are created by molten material spraying over the surface. In 
shielding gas conditions smooth depositions tend to occur with little spatter and with better wetting to the substrate at the deposition edges, Figure 9.

Imaging of the individual splats showed different forms of depositions that the shielding gas conditions created. Rough depositions were most commonly found in the atmospheric deposition conditions. Gashes into the substrate show that either the substrate surface was abrasively removed or exhibit the presence of electrode stick-slip conditions. This is common when the electrode short circuits the arc and solidifies to the substrate before it is pulled away by force ${ }_{4}$. These details may be seen in Figures 7 and 8. Smooth depositions occurred commonly in the Argon shielding gas conditions and left smooth depositions with rounded edges as seen in Figure 11. The 95/5 Ar/ $\mathrm{H}_{2}$ shield gas conditions yielded a rougher topography than the smooth deposition seen in the Argon conditions, but also lacked the characteristics of roughness from streamers seen in air.

A more energetic discharge due to increased conductivity and lower ionization potential with the addition of hydrogen to argon may explain the higher energy discharge that created the topography in Figure 12. Further steps to account for the different pathways of energy loss and transfer would include the theoretical and quantitative energy balance equated to the energy input. Both joule heating conduction and gas conduction and ionization models could be included to account for energy dissipation.

SEM images of the etched cross-sections in Figures 13, 15 and 17 show grain structure in both the base metal and the layered deposition. As seen in welding studies the columnar grain orientation of the depositions is parallel to direction of heat flow 12 . For all three gas conditions epitaxial grain growth was seen through subsequent layers. However depositions in air showed more cracks between layers or bridging defects as well as pores throughout each layer. This decreased the amount of parallel grain structures in the air deposition samples. Grain structures in both Argon and Argon-Hydrogen samples were uniformly parallel. What may be considered a heat affected zone was seen in each deposition where the columnar grain structure in the coating transitions to a base metal grain structure. The heat affected zone was more prominent in the air and argon-hydrogen conditions than in the argon conditions.

Elemental line-scans in Figures 14, 16 and 18 show that dilution was more prominent in air and $\mathrm{Ar} / \mathrm{H}_{2}$ gas conditions. This was seen in the dilution of iron into the deposition. Gradual decrease in concentration of nickel and molybdenum further into the deposition verified this. In the argon gas conditions there was less dilution of the deposition. Both heat affected zone prominence and material dilution suggest that the 304 substrate experienced less heat input in the argon gas conditions despite the hotter electrode conditions.

\section{Conclusions}

This research shows the applicability of different process measurement techniques for different gas conditions. Audio and visual observations are an appropriate first step in roughly evaluating the process quality. Further measurements using of these characteristics using a microphone and video recording further helped to distinguish the differences in process operation and quality. Electrode temperature successfully provided information on the heat dynamics of the process for different shield gases. It was found that the effect of Hydrogen addition to Argon shielding gas during ESD did not increase the heat input as drastically as in other welding processes. Microstructural and EDS analysis shows that more heat input due to the mixed ArgonHydrogen shielding gas conditions caused subtle changes in mixing zones and other microstructure characteristics, but did not create drastic differences in deposition quality. This can be attributed to the low duty cycle and increased shield gas heat transfer to the surrounding system. Individual splat images show that the hydrogenargon shield gases still have the ability to influence splat geometry and therefore quality, but the drastic benefits of penetration and heat input found in conventional welding were not found in the ESD process. 
Bibliography

1. K. R. C. S. Raju, N. H. Faisal, D. S. Rao, S. V. Joshi, and G. Sundararajan, "Electro-spark coatings for enhanced performance of twist drills," Surf. Coat. Technol., vol. 202, no. 9, pp. 1636-1644, Feb. 2008.

2. C. Changjun, S. Yanzhan, C. Qin, and Z. Min, "Study on Cavitation Erosion Properties of Stainless Steel Vane Wheel Enhanced by Electro-Spark Deposition (ESD) Technology," in Advanced Materials, Pts 1-4, vol. 239-242, Z. Cao, X. Q. Cao, L. Sun, and Y. H. He, Eds. Stafa-Zurich: Trans Tech Publications Ltd, 2011, pp. 2229-2232.

3. Tušek, J., and M. Suban. "Experimental Research of the Effect of Hydrogen in Argon as a Shielding Gas in Arc Welding of High-Alloy Stainless Steel." International Journal of Hydrogen Energy 25, no. 4 (April 1, 2000): 369-76. doi:10.1016/S0360-3199(99)00033-6.

4. Lesnjak A., Tusek,J. "Processes and properties of deposits in electrospark deposition." Maney for the inlnstitute of Materials, Minerals and Mining.(26 May, 2002)

5. Nordstrom Richard, Danks Dan. “Data Collection On ASAP Pulses” Internal Journal of The PSU Materials Lab. 20032004

6. Rachel Niedner-Boman. “ESD Arc Discharge Characteristics Final Report” Materials Science Laboratory Report.

7. Thamer, Amin D. "Mechanism of Building-Up Deposited Layer during Electro-Spark Deposition." Journal of Surface Engineered Materials and Advanced Technology 02, no. 04 (2012): 258-63. doi:10.4236/jsemat.2012.2403

8. Norma Price, John Kelley, Mike Egan. "Electro Spark Deposition Process Automation." Advanced Surfaces and Processes Project Report (February 6, 2006) : attached

9. S.K. Tang, T.C. Nguyen, Y. Zhou. "Materials Transfer in Electro-Spark Deposition of TiC $/$ Ni Metal-Matrix Composite Coating on Cu Substrate." Welding Journal: Vol. 89, (August, 2010): 180s-172s.

10. Buscail, H., S. El Messki, F. Riffard, S. Perrier, R. Cueff, and C. Issartel. "Role of Molybdenum on the AISI $316 \mathrm{~L}$ Oxidation at $900{ }^{\circ}$ C." Journal of Materials Science 43, no. 21 (September 17, 2008): 6960-66. doi:10.1007/s10853008-2965-7.

11. Lowke, J. J. "Physical Basis for the Transition from Globular to Spray Modes in Gas Metal Arc Welding." Journal of Physics D: Applied Physics 42, no. 13 (July 7, 2009): 135204. doi:10.1088/0022-3727/42/13/135204.

12. Durgutlu, Ahmet. "Experimental Investigation of the Effect of Hydrogen in Argon as a Shielding Gas on TIG Welding of Austenitic Stainless Steel." Materials \& Design 25, no. 1 (February 2004): 19-23. doi:10.1016/j.matdes.2003.07.004. 